\title{
GAMBARAN HASIL PEMERIKSAAN CT SCAN KEPALA PADA PENDERITA STROKE HEMORAGIK DI BAGIAN RADIOLOGI FK. UNSRAT/SMF RADIOLOGI BLU RSUP PROF. DR. R. D. KANDOU MANADO
}

\author{
${ }^{1}$ Novita T. A. Parinding \\ ${ }^{2}$ Ramli Haji Ali \\ ${ }^{2}$ Vonny N. Tubagus \\ ${ }^{1}$ Kandidat Skripsi Fakultas Kedokteran Universitas Sam Ratulangi Manado \\ ${ }^{2}$ Bagian Radiologi Fakultas Kedokteran Universitas Sam Ratulangi Manado \\ Email:
}

\begin{abstract}
Hemorrhagic stroke is a spontaneous blood vessel bursts inside the brain. The main cause is chronic hypertension and the presence of degeneration of cerebral blood vessels. Bleeding can occur in the brain and the subarachnoid space due to rupture of an artery or rupture of the aneurysm. At a stroke, a CT scan is the gold standard examination to distinguish infarction with bleeding, because CT scan can give a very clear picture of the head of the intracranial space persisted as cerebral infarction, intracranial hemorrhage, and hemorrhagic stroke. So it can be helpful to diagnose the disease and neurological disorders. The purpose of this study is to cognize the distribution of hemorrhagic stroke patients who performed a head CT scan at The Department of Radiology of FK UNSRAT / SMF Radiology of BLU Prof. Dr. R. D. Kandou Manado. This is a retrospective descriptive study by using secondary data coming from hemorragic stroke patients medical records in the Department of Radiology of BLU Prof. Dr. R. D. Kandou Manado on the period time from May to October 2014. Patients admitted inclusion criteria age between 30-80 years old, proven hemorrhagic stroke based on history, physical examination and investigations of doctors. The results showed that the total number of head CT Scans are 296 patients and more showed abnormal picture (58.1\%) compared with the normal picture (41.9\%), there are 64 patients with abnormal CT Scan picture results of hemorrhagic stroke (37.2\% ), patients with hemorrhagic stroke are more common in males (65.6\%), most in the age group of the early elderly betweeb $46-55$ years old (40.6\%) with most bleeding type of intracerebral hemorrhage (87.5\%). Conclusion: Patient that comes with hemorrhagic stroke case or recurrent stroke should undertake a CT Scan of head to assist diagnose and later on can identify the type of bleeding caused by the stroke.
\end{abstract}

Keywords: head CT scan, haemorrhagic stroke

\begin{abstract}
Abstrak: Stroke hemoragik adalah perdarahan spontan di dalam otak. Penyebab utamanya adalah hipertensi kronik dan adanya degenerasi pembuluh darah cerebral. Perdarahan dapat terjadi di dalam otak dan ruang subaraknoid karena ruptur dari arteri atau ruptur dari aneurisma. Pada penyakit stroke, CT Scan merupakan pemeriksaan baku emas untuk membedakan infark dengan perdarahan, karena CT Scan dapat memberikan gambaran kepala yang sangat jelas tentang proses desak ruang intrakranial seperti infark otak, perdarahan intrakranial, dan stroke hemoragik. Sehingga dapat membantu penegakan diagnosis penyakit dan kelainan neurologik. Tujuan penelitian ini untuk mengetahui distribusi penderita stroke hemoragik yang dilakukan pemeriksaan CT Scan kepala di Bagian Radiologi FK UNSRAT/SMF Radiologi BLU RSUP Prof. Dr. R. D. Kandou Manado. Penelitian ini merupakan penelitian deskriptif retrospektif dengan memanfaatkan data sekunder berupa rekam medik pasien stroke hemoragik di Bagian Radiologi BLU RSUP Prof. Dr. R. D. Kandou Manado periode Mei-Oktober 2014. Pasien yang masuk kriteria inklusi yaitu usia 3080 tahun, terbukti stroke hemoragik berdasarkan anamnesis, pemeriksaan fisik dan penunjang oleh dokter. Hasil pemeriksaan CT Scan kepala berjumlah 296 pasien dan lebih banyak
\end{abstract}


menunjukkan gambaran abnormal (58,1\%) dibandingkan gambaran normal (41,9\%), pada gambaran abnormal terdapat 64 penderita dengan hasil CT Scan gambaran stroke hemoragik (37,2\%), penderita stroke hemoragik lebih banyak terjadi pada laki-laki $(65,6 \%)$, paling banyak pada kelompok umur lansia awal 46-55 tahun (40,6\%) dengan tipe perdarahan paling banyak yaitu perdarahan intraserebral (87,5\%). Simpulan : Penderita yang datang dengan keluhan stroke hemoragik atau stroke berulang sebaiknya melakukan pemeriksaan CT Scan kepala untuk membantu diagnosis dan dapat diketahui tipe perdarahan dari stroke tersebut.

Kata kunci : CT scan kepala, stroke hemoragik

Computerized Tomography Scanner (CT Scan) merupakan pemeriksaan khusus mutakhir, tidak berbahaya, sederhana, cepat dikerjakan dan banyak memberikan informasi yang dapat diandalkan. ${ }^{1}$ CT Scan dapat memberikan gambaran kepala yang sangat jelas tentang proses desak ruang intrakranial, misalnya tumor otak, infark otak, abses otak, hidrosefalus, hematoma epidural dan hematoma subdural. ${ }^{2}$ Pada penyakit stroke, CT Scan merupakan pemeriksaan baku emas untuk membedakan infark dengan perdarahan. ${ }^{3}$

Stroke hemoragik adalah adanya perdarahan spontan di dalam otak. Penyebab utamanya adalah hipertensi kronik dan adanya degenerasi pembuluh darah cerebral. Perdarahan dapat terjadi di dalam otak dan ruang subaraknoid karena ruptur dari arteri atau ruptur dari aneurisma. $^{4}$

Lokasi perdarahan stroke hemoragik yang paling sering: putamen dan kapsula interna $( \pm 50 \%)$ dari semua kasus stroke hemoragik, daerah lobus (lobus temporal, parietal, frontal), talamus, pons, serebelum. Lokasi perdarahan bisa sebagai prediktor keluaran stroke hemoragik. ${ }^{4}$

Setiap tahun di Amerika Serikat, sekitar 795.000 orang mengalami stroke yang baru atau berulang. Dari jumlah tersebut, sekitar 610.000 merupakan serangan awal, dan 185.000 merupakan stroke berulang. Studi epidemiologi menunjukkan bahwa sekitar $87 \%$ dari stroke di Amerika Serikat ialah iskemik, $10 \%$ sekunder untuk perdarahan intraserebral, dan lainnya 3\% mungkin menjadi sekunder untuk perdarahan subaraknoid. ${ }^{5,6}$

Prevalensi stroke di Indonesia berdasarkan data Riset Kesehatan Dasar (Riskesdas) tahun 2013 sebesar 7 per mil dan yang terdiagnosis tenaga kesehatan atau gejala sebesar 12,1 per mil. Prevalensi stroke berdasarkan diagnosis nakes tertinggi di Sulawesi Utara (10,8\%), diikuti DI Yogyakarta (10,3\%), Bangka Belitung dan DKI Jakarta masing-masing 9,7\%. Prevalensi Stroke berdasarkan terdiagnosis nakes dan gejala tertinggi terdapat di Sulawesi Selatan (17,9\%), DI Yogyakarta (16,9\%), Sulawesi Tengah (16,6\%, diikuti Jawa Timur sebesar 16\%). Prevalensi penyakit stroke pada kelompok yang didiagnosis nakes berdasarkan gejala meningkat seiring dengan bertambahnya umur, tertinggi pada umur $\geq 75$ tahun $(43,1 \%)$ dan $(67 \%) .^{7}$

Di provinsi Sulawesi Utara sendiri, prevalensi stroke sebesar 10,4\%. Pada tahun 2010 stroke menempati posisi kedua penyakit terbanyak (kasus baru). Pada tahun 2011 stroke kembali menempati posisi pertama penyakit terbanyak (kasus baru) dengan jumlah kasus sebanyak 228 kasus. Peningkatan angka stroke di Indonesia diperkirakan berhubungan dengan peningkatan angka kejadian faktor risiko stroke. Faktor risiko stroke adalah diabetes mellitus, gangguan kesehatan mental, merokok, obesitas dan hipertensi. Hipertensi adalah masalah yang sering dijumpai pada pasien stroke, dan menetap setelah serangan stroke. ${ }^{8}$

Berdasarkan semakin meningkatnya angka kejadian stroke di Indonesia terutama dengan faktor risiko hipertensi maka peneliti ingin mengetahui gambaran hasil pemeriksaan CT Scan kepala penderita stroke hemoragik di Bagian Radiologi BLU RSUP Prof. Dr. R. D. 
Kandou Manado.

\section{METODE PENELITIAN}

Penelitian ini merupakan penelitian deskriptif retrospektif dengan memanfaatkan data sekunder berupa lembaran permintaan dan jawaban CT Scan kepala yang terdapat di Bagian Radiologi BLU RSUP Prof. Dr. R. D. Kandou Manado periode Mei-Oktober 2014. Populasi penelitian yaitu semua lembar permintaan dan hasil CT Scan kepala sedangkan sampel penelitian yaitu semua lembaran permintaan dan hasil CT Scan kepala penderita dengan dugaan klinis stroke hemoragik. Alat dan bahan yang digunakan untuk penelitian ini yaitu buku teks, E-book, jurnal, alat tulis menulis, lembaran permintaan dan hasil CT Scan kepala, alat cetak dan penyimpanan data serta laptop dengan perangkat lunak Microsoft Word dan SPSS versi 20.

Variabel penelitian yang diteliti yaitu:

1. Lembaran permintaan dan hasil CT Scan kepala

2. Usia

3. Jenis kelamin

4. Hasil CT Scan kepala pasien gambaran normal dan abnormal pada penderita stroke hemoragik.

Cara kerja pada penelitian ini yaitu data dikumpulkan secara retrospektif dari lembaran permintaan CT Scan kepala penderita dengan dugaan stroke hemoragik dalam kurun waktu 6 bulan. Data yang terkumpul kemudian diolah dan disajikan dalam bentuk tabel.

\section{HASIL PENELITIAN}

Berdasarkan hasil penelitian di Bagian Radiologi FK Unsrat/SMF Radiologi BLU RSUP Prof. Dr. R. D. Kandou Manado periode Mei-Oktober 2014, didapatkan penderita yang dilakukan pemeriksaan CT Scan kepala sebanyak 296 kasus.

Dari Tabel 1 didapatkan data sebanyak 124 orang $(49,1 \%)$ dengan gambaran normal dan 172 orang (58,1\%) dengan gambaran abnormal. Dari hasil CT Scan kepala abnormal ditemukan sebanyak 64 penderita $(37,2 \%)$ dengan gambaran stroke hemoragik yang merupakan sampel penelitian.

Tabel 1. Distribusi frekuensi penderita stroke hemoragik berdasarkan gambaran normal dan abnormal

\begin{tabular}{ccc}
\hline $\begin{array}{c}\text { Hasil CT } \\
\text { scan } \\
\text { kepala }\end{array}$ & n & $\begin{array}{c}\text { Presentase } \\
\text { (\%) }\end{array}$ \\
\hline Normal & 124 & 41,9 \\
Abnormal & 172 & 58,1 \\
\hline Jumlah & $\mathbf{2 9 6}$ & $\mathbf{1 0 0}$ \\
\hline
\end{tabular}

Berdasarkan data Tabel 2. Jumlah penderita stroke hemoragik yang berjenis kelamin laki-laki sebanyak 42 orang $(65,6 \%)$ sedangkan jumlah perempuan adalah sebanyak 22 orang (34,4\%).

Tabel 2. Distribusi sampel berdasarkan jenis kelamin

\begin{tabular}{ccc}
\hline $\begin{array}{c}\text { Jenis } \\
\text { kelamin }\end{array}$ & n & $\begin{array}{c}\text { Presentase } \\
(\%)\end{array}$ \\
\hline Laki-laki & 42 & 65,6 \\
Perempuan & 22 & 34,4 \\
\hline Jumlah & $\mathbf{6 4}$ & $\mathbf{1 0 0}$ \\
\hline
\end{tabular}

Berdasarkan data Tabel 2. Jumlah penderita stroke hemoragik yang berjenis kelamin laki-laki sebanyak 42 orang (65,6\%) sedangkan jumlah perempuan adalah sebanyak 22 orang (34,4\%).

Tabel 3. Distribusi sampel berdasarkan kelompok umur

\begin{tabular}{ccc}
\hline $\begin{array}{c}\text { Umur } \\
\text { (tahun) }\end{array}$ & $\mathbf{n}$ & $\begin{array}{l}\text { Presentase } \\
\text { (\%) }\end{array}$ \\
\hline $26-35$ & 2 & 3,1 \\
$36-45$ & 9 & 14,1 \\
$46-55$ & 26 & 40,6 \\
$56-65$ & 13 & 20,3 \\
$>65$ & 14 & 21,9 \\
\hline Jumlah & $\mathbf{6 4}$ & $\mathbf{1 0 0}$ \\
\hline
\end{tabular}

Berdasarkan data tabel 3, kelompok umur 46-55 tahun memiliki penderita stroke hemoragik terbanyak dari seluruh kelompok dengan jumlah penderita sebanyak 26 orang (40,6\%), sedangkan 
kelompok umur 26-35 tahun yang paling sedikit dengan jumlah 2 orang (3,1\%).

Tabel 4. Distribusi sampel berdasarkan tipe perdarahan

\begin{tabular}{ccc}
\hline $\begin{array}{c}\text { Tipe } \\
\text { perdarahan }\end{array}$ & n & $\begin{array}{c}\text { Presentase } \\
\text { (\%) }\end{array}$ \\
\hline $\begin{array}{c}\text { Perdarahan } \\
\text { intraserebral }\end{array}$ & 56 & 87,5 \\
$\begin{array}{c}\text { Perdarahan } \\
\text { subaraknoid } \\
\text { Perdarahan } \\
\text { epidural }\end{array}$ & 2 & 3,1 \\
$\begin{array}{c}\text { Perdarahan } \\
\text { subdural }\end{array}$ & 2 & 6,3 \\
\hline Jumlah & $\mathbf{6 4}$ & $\mathbf{1 0 0}$ \\
\hline
\end{tabular}

Berdasarkan data Tabel 4. Tipe perdarahan paling banyak pada penderita stroke hemoragik adalah perdarahan intraserebral sebanyak 56 orang $(87,5 \%)$ dan paling sedikit yaitu pada tipe perdarahan subaraknoid dan epidural masing-masing sebanyak 2 orang dengan presentase masing-masing (3,1\%).

\section{BAHASAN}

Dari hasil penelitian ini, ditemukan sebanyak 296 pasien yang melakukan pemeriksaan CT Scan kepala di Bagian Radiologi FK. Unsrat/SMF Radiologi BLU RSUP Prof. Dr. R. D. Kandou Manado periode Mei-Oktober 2014. Pada tabel 1. didapatkan data sebanyak 172 penderita (58,1\%) dengan gambaran CT Scan kepala abnormal sedangkan sebanyak 124 penderita (41,9\%) dengan gambaran CT Scan normal. 172 penderita dengan gambaran abnormal ditemukan penderita dengan hasil CT Scan kepala stroke hemoragik sebanyak 64 orang (37,2\%). Hasil ini agak berbeda dengan angka kejadian stroke dalam dekade terakhir, dimana penderita stroke hemoragik pada dekade terakhir $\pm 20 \%$ sedangkan pada penelitian ini terdapat $37,2 \%{ }^{4}$

Pada tabel 2. Hasil penelitian mendapatkan data bahwa pasien laki-laki lebih banyak menderita stroke hemoragik yaitu sebanyak 42 orang (65,6\%) dibandingkan perempuan sebanyak 22 orang (34,4\%). Hal ini cukup berbeda dengan penelitian yang dilakukan di kota Makassar tahun 2010-2012, dimana insidensi stroke hemoragik pada laki-laki lebih tinggi daripada perempuan dengan rata-rata $25 \%-30 \%{ }^{9}$ Sedangkan pada penelitian yang dilakukan Anggiamurni L. di RSUP Dr. Kariadi Semarang menunjukkan bahwa penderita dengan stroke hemoragik pada laki-laki lebih banyak dari perempuan (59,2\% : 40,8\%), hasil tersebut sesuai dengan peelitian Sandoval JL. ${ }^{4}$ Hasil tersebut juga serupa dengan penelitian ini dengan jumlah penderita laki-laki yang menderita stroke masih lebih tinggi dibanding perempuan.

Data tabel 3. Didapatkan penderita stroke terbanyak pada kelompok umur 4655 tahun sebanyak 26 orang (40,6\%) dan paling sedikit pada kelompok umur 26-35 tahun sebanyak 2 orang (3,1\%). Hasil tersebut tidak berbeda jauh dengan studi kasus yang dilakukan di RD Dr. Kariadi Semarang, jumlah kasus stroke hemoragik pada usia di atas 49 tahun lebih banyak dibandingkan usia dibawah atau sama dengan 49 tahun (71,4\% : 26,6\%). Hasil ini juga sesuai dengan penelitian Jose LR. Sandoval, MD, et al. ${ }^{4}$

Data tabel 4. Menunjukkan penderita stroke hemoragik dengan tipe perdarahan terbanyak yaitu perdarahan intraserebral sebanyak 56 orang $(87,5 \%)$ dan jumlah paling sedikit dengan tipe perdarahan subaraknoid dan subdural, masing-masing sebanyak 2 orang dengan presentase masing-masing (3,1\%). Berdasarkan penelitian yang dilakukan sebelumnya di BLU RSUP Prof. Dr. R. D. Kandou Manado periode 2012-2013, gambaran CT Scan yang paling sering didapati yaitu perdarahan intraserebral dengan presentase (34\%) yang berbeda jauh yaitu sebesar $(53,5 \%)$ dengan hasil penelitian ini sebesar (87,5\%). Ini menunjukkan bahwa terjadi peningkatan kasus stroke hemoragik dengan tipe perdarahan intraserebral. ${ }^{10}$

\section{SIMPULAN}

Berdasarkan hasil penelitian yang dilakukan di Bagian Radiologi FK 
Unsrat/SMF Radiologi BLU RSUP Prof. Dr. R. D. Kandou Manado periode MeiOktober 2014 mengenai gambaran CT Scan kepala pada penderita stroke hemoragik, dapat disimpulkan bahwa :

1. Hasil pemeriksaan CT scan kepala lebih banyak menunjukkan gambaran abnormal dan paling banyak pada penderita dengan hasil CT Scan stroke hemoragik.

2. Penderita stroke hemoragik lebih banyak pada laki-laki.

3. Penderita stroke hemoragik terbanyak pada usia lansia awal.

4. Penderita stroke hemoragik paling banyak dengan tipe perdarahan intraserebral

\section{DAFTAR PUSTAKA}

1. Mardjono M, Sidharta P. Neurologi Klinis Dasar. Jakarta: Dian Rakyat;2008. p. 472.

2. Harsono. Buku Ajar Neurologi Klinis Dasar. Yogyakarta: Gadja Mada University Press;2011. p.282.

3. Mansjoer A. Suprohaita, Wardhani WI, Setiowulan W, editor. Kapita Selekta Jilid II. Edisi ke-3. Jakarta: Balai Penerbit FKUI;2000. p.19.

4. Anggiamurni L. Correlation Of Hematome Volume And Location With Motor Function Recovery In Hemorrhagic Stroke Patients Using
The Orgogozo Scale [Thesis]. Semarang: Diponegoro University; 2010.

5. Roger VL, Go AS, Lloyd-Jones DM, Benjamin EJ, Berry JD, Borden WB, et al. Heart Disease And Stroke Statistics-2012 update: a report from the American Heart Association. Circulation. Jan 3 2012;125(1): p. e2e220.

6. Shiber JR, Fontane E, Adewale A. Stroke registry: Hemorrhagic vs Ischemic Strokes. Am J Emerg Med. Mar 2010; 28(3) : p. 331-3.

7. Departemen Kesehatan Republik Indonesia. Laporan Hasil Riset Kesehatan Dasar Indonesia (Riskesdas) 2013.

8. Ramadhini AZ, Angliadi LS, Angliadi E. Gambaran Angka Kejadian Stroke Akibat Hipertensi di Instalasi Rehabilitasi Medik BLU RSUP Prof. Dr. R. D. Kandou Manado Periode Januari-Desember 2011. Eclinic. 2011.

9. Sitorus RJ, Hadisaputro S, Kustiowati Endang. Faktor-faktor Risiko Yang Mempengaruhi Kejadian Stroke Pada Usia Muda Kurang dari 40 Tahun. Epidemiologi. 2008.

10.Manasirip ME, Oley MCh, Limpeleh $H$. Gambaran CT Scan Pada Penderita Cedera Kepala Ringan di BLU RSUP Prof. Dr. R. D. Kandou Manado Periode 2012-2013. E-clinic. 2014;2. 